\title{
Análisis de contenido de la lista de distribución IweTel (1998-2000)
}

\author{
Por José Antonio Ontalba y Ruipérez
}

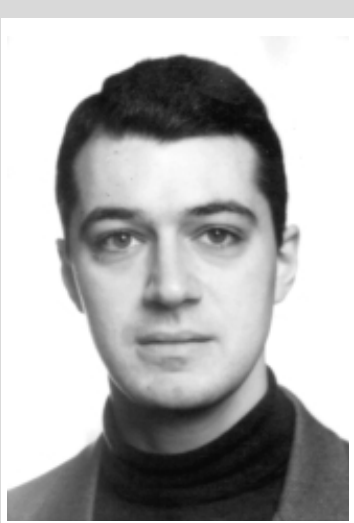

Resumen: La lista de distribución se ha mostrado durante la última década como una herramienta eficaz a la hora de vertebrar la comunicación profesional. De hecho, es un primer paso hacia las comunidades virtuales. En este artículo se estudia la evolución de un caso concreto, IweTel, y del uso que los suscriptores hicieron de él, a partir del análisis de contenido de los mensajes que fueron enviados entre 1998 y 2000. Del estudio se desprende que se trata de una lista utilizada fundamentalmente para la comunicación profesional y el intercambio de información, aunque adolece de una falta notoria de implicación activa por parte de sus suscriptores. Por otro lado, aunque han sido notables las mejoras fruto de la moderación, hay una ausencia viciosa de contenido científico o académico en los debates desarrollados.

Descriptores: Lista de distribución, Lista de discusión, Lista de correo electrónico, Comunidades virtuales, IweTel, Listserv, Análisis de contenido, Comunicación informal.

Title: The IweTel distribution list (1998-2000): A content analysis

Abstract: Throughout the past decade, distribution lists have proved to be an effective tool for articulating professional communication. In fact, they represent a first step towards virtual communities. A specific case — that of IweTel-is presented, including a description of its evolution and how it has been used by subscribers, through a content analysis of messages sent from 1998 to 2000. The study shows the list to be used mainly for professional communication and information exchange. However, it also reveals a surprising lack of active participation by those subscribed. Although the presence of list moderators has contributed to substantial improvements, there continues to be a troubling absence of scientific or academic content in the ongoing debates.

Keywords: Distribution list, Discussion list, Mailing list, Online list, Virtual communities, IweTel, Listserv, Content analysis, Informal communication.

Ontalba y Ruipérez, José Antonio. "Análisis de contenido de la lista de distribución IweTel (1998-2000)”. En: El profesional de la información, 2002, enero-febrero, v. 11, n. 1, pp. 14-27.

\section{Introducción}

Las listas de distribución (también conocidas como foros de debate, listas de correo o listas de discusión) son conjuntos de usuarios de correo electrónico que, agrupados por un interés o afinidad común, intercambian mensajes a través de un servidor de listas (encargado de distribuirlos a todos los suscriptores) para solventar sus necesidades de información y comunicación sobre la temática que los congrega.

Entre otras ventajas, las listas permiten: formular preguntas que se dirigen a cientos de colegas simultáneamente, recibir los mensajes directamente en el buzón y enviarlos o leerlos en cualquier momento, formarse una opinión del estado de la profesión, acceder a la información formal e informal, establecer vínculos con profesionales del mismo campo de interés, enriquecerse de ideas y críticas con colegas reconocidos, o disfrutar de un estatus de igualdad entre emisores y receptores.

Por consiguiente son un cauce privilegiado para estar continuamente al día de los ámbitos de interés.

Recibido el 13-8-01

A ceptación definitiva: 28-12-01
Por medio de ellas, los profesionales de la información (o cualquier otro) pueden conocer las actividades y programas desarrollados por otros centros, cooperar, compartir recursos, consultar dudas (remitiendo posteriormente a la lista una recopilación de las respuestas recibidas) e intercambiar experiencias a la hora de po-

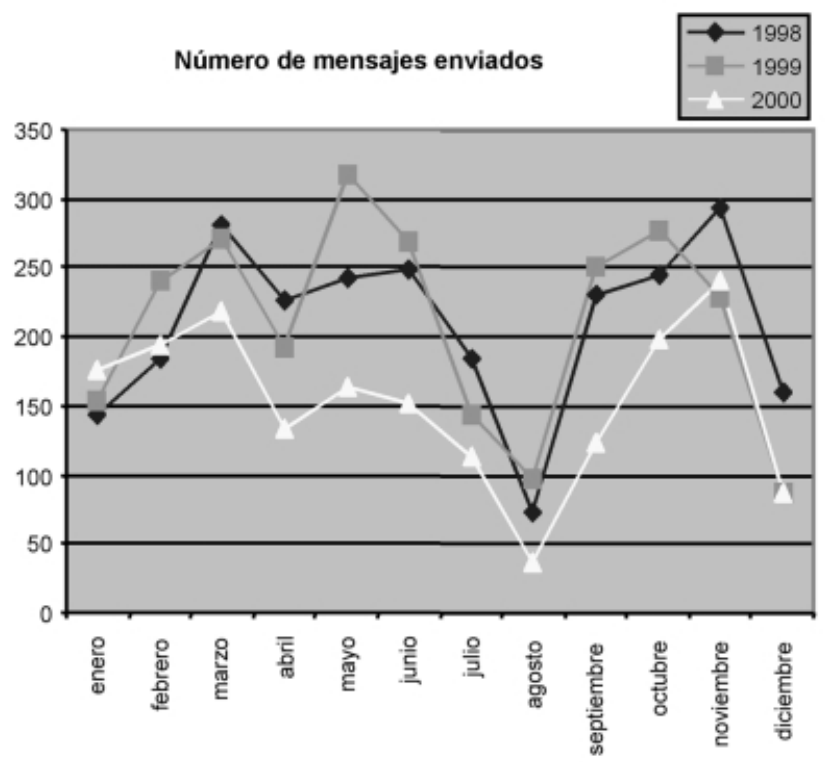

Gráfico 1: Distribución mensual del envío de mensajes 
ner en marcha nuevos proyectos. Considerada últimamente como un primer paso en el camino hacia las comunidades virtuales, la lista es, en definitiva, una forma de comunicación muy viva y dinámica.

Entre final de la década de los 80 y principio de la de los 90 se dio una oleada de foros electrónicos en las redes. En el ámbito de los profesionales de la informa- ción destacaban Pacs_l (Public-access computer services), Buslib-l (Business librarians) y Asis-l (American Society for Information Science).

Como es habitual, en el ámbito castellanohablante hubo que esperar unos años. En noviembre de 1993 nació IweTel en los ordenadores de la entonces empresa Spritel (hoy Sarenet). Fue creada por Tomàs Baiget

\begin{tabular}{|c|c|c|c|c|c|c|c|c|c|c|c|c|c|c|c|c|}
\hline & \multicolumn{3}{|c|}{$\begin{array}{c}\text { INTERCAMBIO } \\
\text { DE } \\
\text { INFORMACIÓN }\end{array}$} & \multicolumn{3}{|c|}{ ANUNCIOS } & \multicolumn{2}{|c|}{ NOVEDADES } & \multirow{2}{*}{ 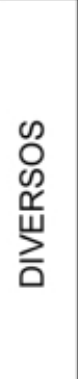 } & \multirow{2}{*}{ 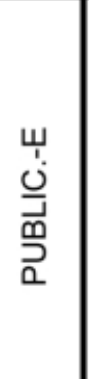 } & \multirow{2}{*}{ 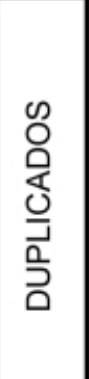 } & \multirow{2}{*}{ 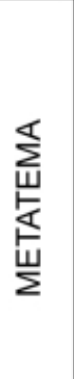 } & \multirow{2}{*}{ 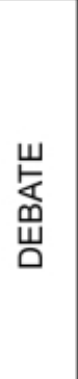 } & \multirow{2}{*}{ 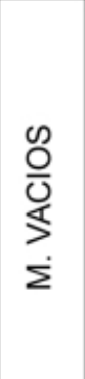 } & \multirow{2}{*}{ 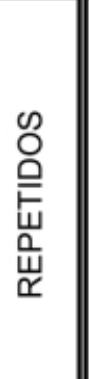 } & \multirow[b]{2}{*}{$\begin{array}{l}\overrightarrow{5} \\
\text { O } \\
\circ\end{array}$} \\
\hline & 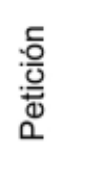 & 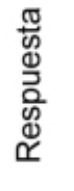 & :을 & 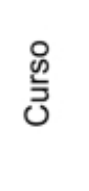 & 总 & 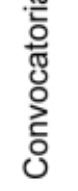 & 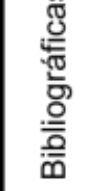 & 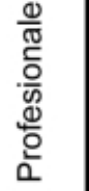 & & & & & & & & \\
\hline \multicolumn{17}{|c|}{1998} \\
\hline Enero & 51 & & 0 & 16 & 16 & 3 & 8 & 13 & 7 & 6 & 2 & 0 & 0 & 4 & 2 2|| & 144 \\
\hline Feb & 54 & 12 & 2 & 16 & 15 & 10 & 4 & 22 & 22 & 9 & 7 & 0 & & 1 & 2 & 84 \\
\hline Marzo & 76 & 36 & 4 & 15 & 30 & 17 & 12 & 23 & 19 & 8 & 17 & 2 & 0 & 13 & $10 \|$ & 282 \\
\hline Abril & 53 & 12 & 3 & 17 & 32 & 15 & 5 & 14 & 16 & 12 & 13 & 7 & 11 & 13 & 3|| & 226 \\
\hline Mayo & 59 & 14 & 4 & 14 & 20 & 10 & 12 & 18 & 11 & 14 & 10 & 5 & 33 & 8 & $11 \|$ & 243 \\
\hline Junio & 47 & 10 & 3 & 13 & 16 & 9 & 10 & 18 & 21 & 18 & 6 & 4 & 53 & 16 & $4 \|$ & 248 \\
\hline Julio & 49 & 9 & 1 & 11 & 8 & 10 & 9 & 12 & 11 & 18 & 이 & 7 & 17 & 14 & $8 \|$ & 84 \\
\hline $\mathrm{Ag}$ & 27 & 6 & 1 & 4 & 9 & 2 & 1 & 2 & 2 & 9 & 이 & 0 & 2 & 5 & $3 \|$ & 8 \\
\hline bre & 61 & 34 & 0 & 14 & 18 & 3 & a & 17 & 16 & 12 & 16 & 0 & 16 & 10 & $4 \|$ & 230 \\
\hline Octu & 73 & 26 & 2 & 15 & 22 & 3 & 9 & 25 & 14 & 14 & 9 & 0 & 2 & 28 & 3 || & 245 \\
\hline Noviembre & 95 & 31 & 5 & 11 & 22 & 8 & 8 & 20 & 13 & 13 & 9 & 1 & 38 & 12 & 7 & 293 \\
\hline Dicie & 49 & 5 & 5 & 9 & 5 & 7 & 7 & 10 & 18 & 8 & 12 & 3 & 5 & 16 & 1 & 160 \\
\hline Total & 694 & 211 & 30 & 155 & 213 & 97 & 94 & 194 & 170 & \begin{tabular}{ll|}
141 \\
\end{tabular} & $\begin{array}{l}101 \\
\end{array}$ & 29 & 177 & 148 & 58 & 2512 \\
\hline \multicolumn{17}{|c|}{1999} \\
\hline Ener & 43 & 17 & 1 & 12 & 10 & 9 & 10 & 22 & 6 & 6 & 4 & 3 & 0 & 9 & $11 \mid$ & $\overline{153}$ \\
\hline Febrero & 50 & 13 & 10 & 14 & 19 & 18 & 8 & 21 & 22 & 19 & 9 & 1 & 16 & 17 & $3 \|$ & 240 \\
\hline Marzo & 51 & 19 & 5 & 15 & 19 & 11 & 8 & 19 & 19 & 24 & 10 & 6 & 54 & 6 & $5 \|$ & 271 \\
\hline Abril & 26 & 7 & 0 & 14 & 26 & 14 & 10 & 14 & 15 & 19 & 2 & 6 & 15 & 19 & 5 & 192 \\
\hline Mayo & 55 & 31 & 2 & 16 & 24 & 12 & 7 & 14 & 25 & 43 & 7 & 1 & 45 & 18 & $17 \|$ & 317 \\
\hline Junio & 42 & 16 & 3 & 18 & 17 & 9 & 8 & 26 & 32 & 32 & 5 & 8 & 24 & 27 & 2 & \\
\hline Julio & 36 & 15 & 1 & 10 & 6 & 7 & 11 & 9 & 5 & 14 & 7 & 3 & 0 & 16 & $3 \|$ & 143 \\
\hline Agost & 28 & 3 & 3 & 6 & 10 & 4 & 3 & 3 & 6 & 10 & 3 & 2 & I & 13 & $4 \|$ & \\
\hline bre & 58 & 32 & 2 & 20 & 9 & 15 & 8 & 15 & 19 & 7 & 13 & 0 & 40 & 9 & $3 \|$ & 0 \\
\hline Octub & 70 & 48 & 5 & 20 & 16 & 17 & 12 & 13 & 27 & 6 & 10 & 2 & 이 & 20 & $12 \|$ & 278 \\
\hline No & 89 & 27 & 2 & 12 & 10 & 10 & 16 & 13 & 16 & 이 & 10 & 4 & 0 & 10 & 9 & 228 \\
\hline Diciembre & 25 & 4 & 0 & 2 & 10 & 5 & 15 & 17 & 2 & 0 & 2 & 0 & 5 & 1 & 0 & \\
\hline Total & 573 & 232 & $\overline{34}$ & 159 & 176 & 131 & 116 & 186 & 194 & 180 & 82 & 36 & 199 & 165 & 64 & $20<1$ \\
\hline
\end{tabular}

\begin{tabular}{|l|rrr|rrr|rr|r|r|r|r|r|r|r||r||}
\hline Enero & 42 & 7 & 1 & 9 & 17 & 7 & 6 & 19 & 8 & 0 & 10 & 3 & 45 & 3 & 0 & 177 \\
Febrero & 33 & 9 & 7 & 23 & 11 & 15 & 12 & 14 & 20 & 0 & 11 & 1 & 37 & 1 & 1 & 195 \\
Marzo & 51 & 19 & 5 & 22 & 27 & 12 & 4 & 25 & 18 & 0 & 8 & 0 & 24 & 2 & 1 & 218 \\
Abril & 34 & 17 & 2 & 9 & 13 & 10 & 9 & 9 & 13 & 1 & 7 & 1 & 9 & 0 & 0 & 134 \\
Mayo & 32 & 20 & 3 & 19 & 26 & 9 & 9 & 19 & 8 & 0 & 15 & 1 & 0 & 0 & 2 & 163 \\
Junio & 29 & 30 & 6 & 10 & 14 & 14 & 6 & 17 & 5 & 0 & 9 & 2 & 7 & 0 & 2 & 151 \\
Julio & 25 & 10 & 8 & 5 & 6 & 12 & 3 & 10 & 11 & 0 & 7 & 1 & 9 & 7 & 0 & 114 \\
Agosto & 11 & 4 & 3 & 3 & 3 & 6 & 0 & 3 & 2 & 0 & 1 & 0 & 0 & 0 & 0 & 36 \\
Septiembre & 24 & 8 & 2 & 19 & 11 & 15 & 12 & 10 & 9 & 0 & 13 & 0 & 0 & 0 & 0 & 123 \\
Octubre & 37 & 17 & 4 & 19 & 20 & 12 & 6 & 21 & 22 & 0 & 19 & 2 & 14 & 3 & 2 & 198 \\
Noviembre & 37 & 59 & 6 & 12 & 12 & 17 & 7 & 9 & 16 & 0 & 5 & 2 & 56 & 3 & 0 & 241 \\
Diciembre & 16 & 10 & 4 & 2 & 5 & 10 & 8 & 9 & 17 & 0 & 4 & 1 & 1 & 0 & 0 & 87 \\
\hline Total & 371 & 210 & 51 & 152 & 165 & 139 & 82 & 165 & 149 & 1 & 109 & 14 & 202 & 19 & 8 & 1837 \\
\hline
\end{tabular}

\begin{tabular}{|l|l|l|l|l|l|l|l|l|l|l|l|l|l|l|l|l|}
\hline \hline TOTAL & 1638 & 653 & 115 & 466 & 554 & 367 & 292 & 545 & 513 & 322 & 292 & 79 & 578 & 332 & 130 & 6876 \\
\hline
\end{tabular} 
y Pedro Hípola, que buscaban un canal de información profesional más rápido a la hora de comunicar noticias recientes de lo que ya en aquel momento era la revista Information world en español (IWE). La división latinoamericana de Swets Subscription Services se encargó de patrocinarla.

Al principio, los usuarios se conectaban a IweTel a través de internet, Iberpac (X.25) o la red telefónica conmutada al sistema de correo electrónico y teleconferencias Euskom (de Spritel). Más tarde se pasó a usar el sistema Majordomo y se creó un servicio gopher para acceder al archivo de mensajes de la lista.

\section{«Con unos 4.200 suscriptores a finales de 2001, IweTel es la mayor lista profesional en len- gua castellana»}

Ante las dimensiones que estaba adquiriendo (cerca de 1.000 suscriptores), a principios de 1997 la lista pasó a estar gestionada desde los ordenadores de la RedIris, donde continúa hasta la fecha. El 30 de noviembre de 1999 los creadores de IweTel decidieron moderarla ante el gran número de mensajes erróneos o inadecuados que llegaban a la lista. Actualmente, no sólo es pionera sino que, con unos 4.200 suscriptores a finales de 2001, es la mayor lista profesional en lengua castellana.

Como canales informales de comunicación que son, las listas de distribución no sólo han abierto nuevas dimensiones en la información científica y profesional, y además permiten ser analizadas como antes no lo había sido ningún otro canal informal. De hecho, ya se han realizado estudios que se incluyen en la bibliografía y que son muestra del potencial de las listas de distribución, así como de los problemas que han ido surgiendo con su desarrollo; entre otras: Serialst, Pubyac, Techwr-l, Teletrabajo, Bib-Med, etc. En todas ellas se advierte un éxito inicial de suscripciones y de envío de mensajes que posteriormente ha llevado a una estabilidad en el número de ellos o incluso a una repetición de los temas y falta de renovación de conteni-

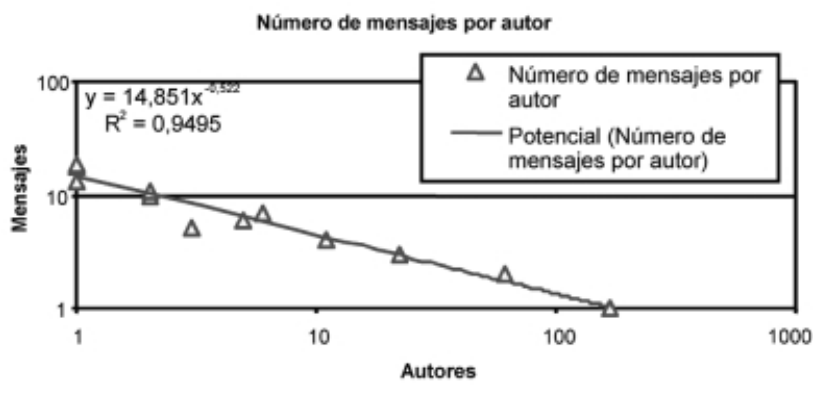

Gráfico 2: Curva de regresión del número de mensajes por autor

\begin{tabular}{|r|r|r|}
\hline $\mathbf{N}^{\circ}$ mensajes/autor & $\mathbf{N}^{\circ}$ de autor & Porcentaje \\
\hline 1 & 166 & 59,0 \\
\hline 2 & 61 & 21,7 \\
\hline 3 & 22 & 7,8 \\
\hline 4 & 11 & 3,9 \\
\hline 5 & 3 & 1,0 \\
\hline 6 & 5 & 1,8 \\
\hline 7 & 6 & 2,1 \\
\hline 10 & 2 & 0,7 \\
\hline 11 & 2 & 0,7 \\
\hline 13 & 1 & 0,4 \\
\hline 18 & 1 & 0,4 \\
\hline 19 & 1 & 0,4 \\
\hline
\end{tabular}

Tabla 2: Porcentaje del número de mensajes por autor

dos, con la participación menos activa de algunos miembros.

Con todo, más adelante se comenta de manera más desarrollada la evolución específica que ha seguido IweTel.

Entre otros beneficios, estudios de este tipo podrían arrojar luz sobre el uso y la satisfacción que la lista genera en los suscriptores, cuestión que no es fácil saber con certeza. A pesar de que las listas varían mucho dependiendo de sus objetivos, del número y tipo de mensajes recibidos, de la participación de los miembros y de la calidad de la discusión, lo que debe ser una preocupación extensible a todas ellas es conocer en qué medida cumplen sus fines ${ }^{1}$.

En el presente artículo se realiza un estudio descriptivo de la lista de distribución paradigmática en el ámbito de la Biblioteconomía y Documentación castellanohablante: IweTel. Se ha buscado con ello dibujar una imagen, más o menos acertada, de la evolución del uso de la lista que han hecho los profesionales de la información, procurando concluir con un enfoque prospectivo.

\section{Material y métodos}

Para alcanzar los fines propuestos, se desarrolla un análisis de contenido descriptivo longitudinal retrospectivo de los 6.876 mensajes remitidos entre 1998 y 2000 a la lista de distribución IweTel. El estudio se limita a tal marco cronológico pues eran los únicos años que se conservan íntegros en los archivos de IweTel durante la elaboración del presente texto ${ }^{2}$.

Las variables objeto de este estudio son:

1) Período temporal de emisión del mensaje (mes/año), a fin de denotar la evolución del número de mensajes producidos en este período y su distribución temporal a lo largo de los meses del año.

2) Autoría, con la intención de identificar el género, la procedencia geográfica, la filiación personal de quienes firman los mensajes, fijando las pautas de pro- 
ductividad de la lista. En los tres casos se ha contabilizado cuántas personas intervienen en cada categoría, y además el número de mensajes de cada una de ellas.

El análisis de esta variable se circunscribe únicamente a los mensajes que forman parte de los debates $(\mathrm{n}=578)$, pues éstos son una de las categorías que requieren una mayor implicación por parte de los miembros de IweTel.

Evidentemente, la muestra en ningún caso es representativa, pues sólo es una de las 15 categorías posibles y no la más abundante (en torno al 10\%); si se hubiera querido hacer una muestra representativa se debería haber efectuado una selección de ésta mediante un proceso de muestreo estratificado.

\section{«Las grandes categorías de los mensajes podrían agruparse en: intercambio de información, anuncio, debate y ruido»}

En lo referente a la procedencia geográfica, hay que dilucidar en primer lugar si ésta se trata de una lista nacional o internacional: el 79,4\% de los mensajes y el $85,3 \%$ de los autores demuestran que es lo primero. En segundo lugar, se ha estudiado tal aspecto estructurándolo por provincias. No obstante, dificultades de identificación han obligado a crear nuevos grupos:

—uno denominado genéricamente "España" y en el que se encuentran aquellos mensajes que indicaban un origen español aunque sin mayor aclaración.

-otro designado como "Iberoamérica", conformado por Argentina, Chile, Colombia, Costa Rica, $\mathrm{Cu}$ ba, Méjico, Perú, Uruguay y Venezuela.

-y un último, "Europa/EUA", donde se incluyen Bélgica, Portugal, República Checa y Suecia (además del país norteamericano).

En cuanto al ámbito profesional se han agrupado en cinco categorías:

-Universidad: mensajes tanto de profesores universitarios, como de bibliotecarios de universidades, como de estudiantes.

-Administración: aquellas personas que trabajan en algún área de la Administración pública (museos, archivos, hospitales, centros culturales, embajadas, ayuntamientos, gobiernos autonómicos, nacionales o estatales...).

-No identificado: en este caso no ha podido ser reconocido el ámbito profesional del autor.

-Empresa/entidad privada: mensajes originados desde la empresa o desde alguna entidad privada (fun- daciones, asociaciones, organizaciones, colegios oficiales, etc.).

-Biblioteca pública: bibliotecas nacionales, bibliotecas públicas del Estado, regionales/autonómicas, comarcales o municipales.

\section{«Mientras que los meses con menor actividad son abril, agosto y diciembre (coincidien- do con las vacaciones), los que presentan mayor movimiento son marzo y noviembre»}

Para terminar, el análisis no ha estado exento de dificultades, puesto que en no pocos mensajes faltaba información que permitiera identificar claramente algunos de los aspectos a estudiar. Un caso claro es la falta de correspondencia entre el nombre que aparece en la dirección de correo electrónico y la firma del mensaje (fuente principal de información al respecto), la cual no aparece o lo hace de manera incompleta. Si bien esta dificultad se ha dado indistintamente en los tres aspectos, ha incidido más a la hora de distinguir el área profesional de la autoría.

3) Análisis temático, con el fin de evidenciar los contenidos y la orientación temática de la lista.

Para tal caso se ha diseñado una clasificación basada en las propuestas de McElhearn (1996) y Peder$\operatorname{sen}(1996 a)$.

McElhearn (1996), basándose en el paralelismo existente entre la comunicación oral y la escrita, reconoce tres categorías:

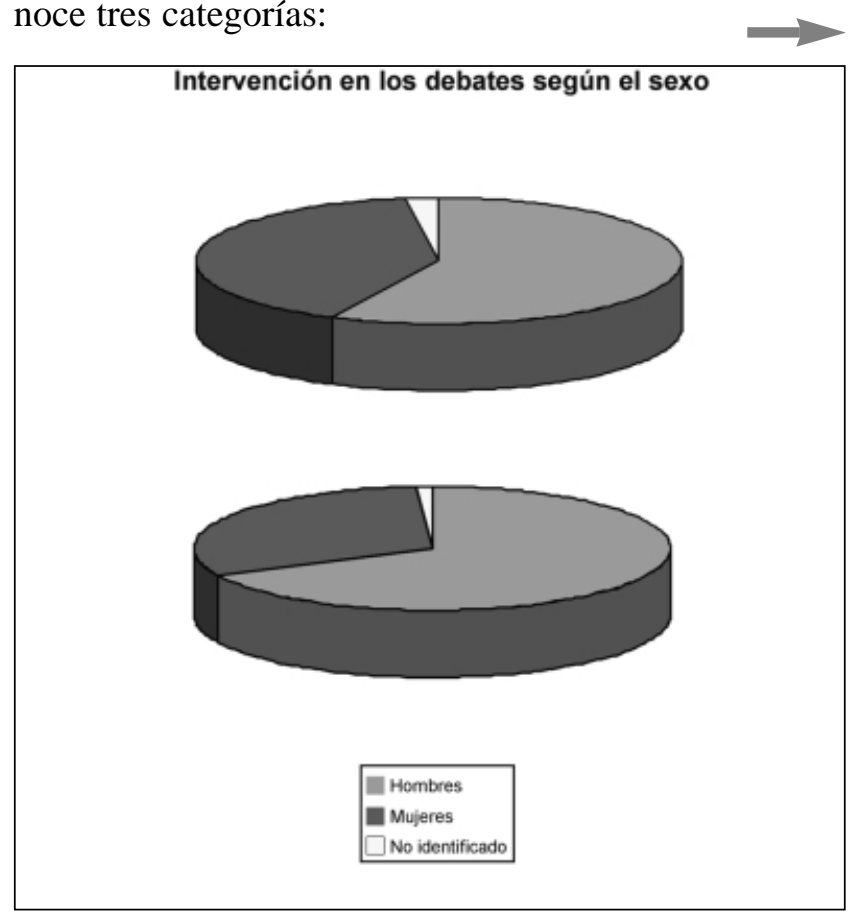

Gráfico 3: Porcentaje según sexo (autores y mensajes) 


\begin{tabular}{|l|l|c|}
\hline \multicolumn{1}{|c|}{ Nombre } & Lugar de trabajo & No de mensajes $^{\circ}$ \\
\hline Paco López Hernández & Universidad Carlos III de Madrid & 19 \\
\hline Alejandro Martínez Andaluz & Universidad Politécnica de Madrid & 18 \\
\hline Ángel Luis Redero Hernández & Universidad de Salamanca & 13 \\
\hline Álvaro Roldán López & Baratz & 11 \\
\hline Gerardo J. Rodríguez Seoane & Técnicas de Formación S. A. & 11 \\
\hline Antonio Galán Gall & Universidad de Castilla-La Mancha & 10 \\
\hline Guillermo Sánchez Martínez & Universidad Pública de Navarra & 10 \\
\hline
\end{tabular}

Tabla 3: Autores más productivos

- el anuncio, que puede ser oficial (conferencia, congreso), simple (por ejemplo, notificación de una nueva sede web), o personal (cambio de trabajo, ausencia por vacaciones).

- la solicitud de información (la mayoría de mensajes): empieza con la petición de información, sigue con la respuesta (una o varias) y a veces finaliza con el mensaje-resumen de respuestas recibidas y agradecimiento, que delimita el final del ciclo, dando por cerrada la cuestión.

- la discusión: puede ser corta y sencilla, o durar largos períodos de tiempo. En cualquier caso, su desarrollo es más complejo que los anteriores.

\section{«Hay una cifra baja (13,7\%) de peticiones de información que acaban haciendo públicas las respuestas recibidas»}

Pedersen (1996a) es más pródigo y divide los mensajes hasta en nueve clases diferentes, las cuales son recogidas en parte y adaptadas por Merlo y Sorli (1998) a su análisis: solicitud de información, discusiones, publicaciones electrónicas, informaciones bibliográficas, informaciones profesionales, oferta de duplicados, organización de la lista, mensajes inapropiados.

En el presente trabajo se proponen, utilizando las aportaciones anteriores, un total de quince categorías entre principales y secundarias que han de identificar de manera unívoca a cada mensaje. La intención de este incremento de categorías no es otra que intentar sacar a la luz la máxima información que la lista pueda ofrecer sobre ella misma, con el fin de obtener resultados lo más ilustrativos posible. Las categorías propuestas son las siguientes:

\section{Intercambio de información}

-Petición: solicitud de información de todo tipo; de contacto con ciertos profesionales; sobre convocatorias, cursos, etc.; de experiencias previas; sobre concepción, desarrollo y gestión de un servicio; incluye, además, encuestas y estudios.
-Respuesta: contestación directa a alguna petición de información concreta.

-Difusión: recopilación y envío a la lista de la información recibida en respuesta a una solicitud hecha por el autor de la compilación.

\section{Anuncios}

-Curso: anuncios de cursos y ofertas formativas regladas o no.

-Evento: divulgación de noticias relacionadas con la celebración de congresos, jornadas, conferencias, simposios, presentaciones, exposiciones, y otro tipo de actividades profesionales; no sólo anuncio del evento, sino también novedades (cambios) en el desarrollo de éste y otras noticias.

- Convocatoria: ofertas de trabajo, becas, ayudas a proyectos, concursos, colaboración en grupos de investigación, certificación, etc.

\section{Novedades}

-Bibliográficas: publicación de informes; borrador de guías, tesauros, publicaciones...

-Profesionales: nombramientos; ofertas, acceso gratuito a bases de datos hasta cierta fecha; divulgación de novedades profesionales. Incluye anuncios de nuevos softwares y servicios, informes sobre novedades, transformaciones en facultades, novedades legislativas, noticias, cambio de dirección profesional.

\section{Diversos}

Difusión de mensajes de diferente naturaleza; avisos de virus, reflexiones personales, protestas, denuncias, reivindicaciones, manifestaciones de solidaridad, posicionamientos públicos individuales o institucionales, cartas abiertas, mensajes de opinión, artículos sobre temas de interés paralelo al profesional con ánimo de provocar debate (sin conseguirlo), textos profesionales de diversa temática, chistes, divulgación de recursos, etc.

\section{Publicaciones electrónicas}

Boletines electrónicos a texto completo que en el caso de IweTel se han limitado a My News y Extra!- 
Net; no se han incluido, por ejemplo, boletines de sumarios de publicaciones impresas.

\section{Duplicados}

Anuncios de oferta y canje de colecciones de duplicados y donaciones de publicaciones.

\section{Metatema}

Los que versan sobre el uso de la lista, consejos de estilo, redacción de los temas, intervenciones de los moderadores (cambios en IweTel, aumento del número de suscriptores), etc.

\section{Debate}

Discusiones e intercambio de opiniones sobre un tema específico siempre que supere el número de cuatro mensajes.

\section{Mensajes vacíos}

Aquellos que son erróneos, inapropiados o personales, solicitudes de altas o bajas, correcciones de mensajes propios enviados antes, felicitaciones, agradecimientos, etc. Actualmente la mayoría de éstos no son aprobados por los moderadores y no se distribuyen.

\section{Repetidos}

Los enviados más de una vez a la lista.

Siguiendo a McElhearn (1996), los quince tópicos podrían agruparse en tres grandes bloques, a los que aquí se ha añadido un cuarto:

-Intercambio de información: petición, respuesta y difusión.

-Anuncio: anuncios de eventos, cursos y convocatorias; novedades profesionales y bibliográficas; diversos; duplicados; metatema.

-Debate.

—Ruido: mensajes vacíos y repetidos.

\begin{tabular}{|l|r|r|}
\hline & Autores & Mensajes \\
\hline Madrid & 23,1 & 31,0 \\
\hline Barcelona & 12,0 & 11,8 \\
\hline La Coruña & 3,9 & 4,7 \\
\hline Valencia & 3,2 & 1,7 \\
\hline Salamanca & 2,1 & 3,8 \\
\hline Resto provincias & 32,6 & 29,7 \\
\hline España sin identif. & 2,5 & 2,6 \\
\hline Iberoamérica & 11,0 & 8,1 \\
\hline Europa y EUA & 1,8 & 2,0 \\
\hline Sin identificar & 7,8 & 4,6 \\
\hline
\end{tabular}

Tabla 4: Porcentajes de la procedencia geográfica de los autores de los mensajes
Como sistema de recuento se ha utilizado el criterio de asignación única (una categoría temática por mensaje). Sin embargo, nos encontramos con problemas de interpretación propios de cualquier sistema de clasificación: hay mensajes que podrían adecuarse a más de una temática pero que, para su identificación unívoca, en este estudio se han encuadrado de manera excluyente sólo en una.

\section{«Participa un mayor número de hombres que de mujeres, los cuales también envían más mensajes»}

Por ejemplo, en septiembre de 1999 hubo una profusión de mensajes sobre la celebración del patrono de la profesión en la que no faltó el debate; sin embargo no todos formaban parte de la discusión: al principio hubo alguno que felicitaba a todos por el día de la profesión (vacíos), otros que explicaban cuándo se conmemoraba en su país (diversos) y otros que planteaban la adecuación de tales mensajes a los objetivos de la lista (debate). En medio de esta mezcolanza, un suscriptor decidió formular la pregunta sobre cuándo se celebraba el día de la profesión en los diferentes países, por lo que los remitidos en tal sentido desde entonces son considerados respuestas.

Caso parecido es lo que dio de sí el tema de la biblioteca en el cine. Desarrollado en noviembre de 2000, se enviaron decenas de mensajes mencionando y describiendo películas en las que la biblioteca o el bibliotecario aparecieran aun de soslayo. Sin embargo, no son sino respuestas a una petición que solicitaba información al respecto. Evidentemente, tal plétora no quedó exenta de debate.

Además, en el presente estudio no se ha aplicado ningún sistema de control de fiabilidad de la observación que se ha llevado a cabo (test-retest, test-test, testnorma), por lo que sufre las limitaciones propias de esta ausencia y los resultados pueden estar sesgados.

Para el análisis de los datos se han empleado índices de frecuencias absolutas y relativas.

\section{Resultados y discusión}

\subsection{Evolución de la producción de mensajes}

Tal y como puede comprobarse en la tabla 1 y el gráfico 1 , su número se mantiene estable en los primeros años, disminuyendo notablemente en el 2000, seguramente como efecto de la moderación de la lista (desde el 30 de noviembre de 1999) ${ }^{3}$.

A lo largo de los días (1.096) que transcurrieron entre 1998 y 2000 se envió un total de 6.876 mensajes, 
lo que supone una media de algo más de 6 por día. Esta cifra no es en absoluto significativa, puesto que se observa, asimismo, que durante los meses correspondientes a las diversas vacaciones (abril, agosto y diciembre) se reduce la actividad misiva de manera destacable; los meses con mayor movimiento acostumbran a ser marzo y noviembre.

\subsection{Autoría}

Como se ha indicado previamente, a la hora de dibujar el perfil correspondiente a los suscriptores de IweTel, se ha querido incidir en tres aspectos específicos: el género, la procedencia geográfica y la filiación profesional de quienes firman los mensajes.

Sin embargo, como la población sobre la que se podía actuar era muy amplia, se ha escogido una muestra hasta cierto punto representativa. Así, se han seleccionado sólo aquellos mensajes que forman parte de los debates, por la razón esgrimida en el punto 2 "Materiales y métodos".

Los 578 mensajes que forman parte de los debates de la lista han sido firmados por 281 autores, lo que significa que el número de mensajes por autor es de 2 . La distribución de los mensajes según autores que participan en los debates de IweTel muestra una curva exponencial decreciente que se aproxima al tipo de comportamiento que quiere reflejar la ley de Lotka (gráfico 2$)^{4}$. Si se observa la tabla 2 se advertirá que las personas que remiten uno o dos mensajes son un $80 \%$ del total de los participantes en las discusiones, y que ese porcentaje envía el 50\% de mensajes (288 de un total de 578). Es digno de mención, asimismo, que por encima de 4 mensajes por autor sólo hay un porcentaje de 7,6 sobre el total de autores. Existe, pues, un grupo de personas relativamente pequeño que dirige la mayoría de las discusiones (minoría activa o "masa crítica"); esa tendencia es típica de la comunicación y la transferencia de información.

En cuanto al género de los autores (gráfico 3), se observa que participan más hombres que mujeres (57,3\% frente a $40,6 \%)$, y que éstos intervienen con un mayor número de mensajes $(67,7 \%$ frente a $31,3 \%)$. Estos datos contrastan que en una profesión eminentemente femenina sean los varones más activos en la publicación.

\begin{tabular}{|l|r|r|}
\hline & \multicolumn{1}{l|}{ Autores } & \multicolumn{1}{c|}{ Mensajes } \\
\hline Universidad & 36,2 & 40,5 \\
\hline Administración & 20,2 & 19,9 \\
\hline Empresa/entidad privada & 14,6 & 13,5 \\
\hline Biblioteca pública & 11,0 & 11,1 \\
\hline No identificado & 18,0 & 15,0 \\
\hline
\end{tabular}

Tabla 5: Porcentajes del ámbito profesional de los autores de los mensajes
Los resultados referentes a la procedencia geográfica (tabla 4), y considerando IweTel como lista nacional, arrojan un predominio claro de Madrid tanto en el número de personas que participan como, sobre todo, en la cantidad de mensajes enviados. En segundo lugar queda Barcelona. Estas cifras no sorprenden, puesto que es evidente el motor profesional en el que se han convertido ambas ciudades hace mucho tiempo. Sí que resulta inesperado que La Coruña ocupe el tercer lugar, por detrás de Iberoamérica y de los mensajes sin lugar de origen identificado, pero por delante de todas las demás provincias españolas.

El ámbito profesional (tabla 5) ha sido el más difícil de dilucidar ante la pobreza de información biográfica que los autores incluyen en sus mensajes. Con todo, y siguiendo la estructura propuesta anteriormente, los datos arrojan cierta luz a este respecto.

\section{«Los temas voluminosamente predominantes en los debates han sido los problemas labora- les y las funciones de las bi- bliotecas, al grado de llegar a superar el $80 \%$ de intervencio- nes enviadas a los debates en el año 2000»}

El universitario se muestra, de largo, como el ámbito más activo con más de un tercio del total de mensajes. Dentro de su porcentaje hay que desglosar el correspondiente a las universidades no españolas: $\mathrm{Cama-}$ güey (Cuba), Piura (Perú), Villa María (Argentina), Boras (Suecia), Los Andes (Venezuela), Autónoma de Nuevo León (Méjico), Lima (Perú), Lovaina (Bélgica) y Católica del Norte (Chile). Éstas suponen un 3,2\% del total de personas y el $2,8 \%$ de mensajes del total profesional.

La Administración copa una quinta parte de personas y mensajes remitidos, con una porción muy similar en ambos asuntos. El Cindoc, dentro de esta categoría, colabora con el $1 \%$ y el 1,9\% para cada caso.

Por otra parte destaca el elevado porcentaje de mensajes en los que no se puede identificar el área profesional (18\% de las personas que intervienen, y 15\% de mensajes enviados), por delante del ámbito de la empresa o de la biblioteca pública. Resulta ésta una cuestión sobre la que se ha de incidir desde la moderación y la administración de la lista.

A señalar que, en el caso de las bibliotecas públicas, las municipales intervienen con $4,3 \%$ y $4 \%$, y las nacionales con el $1,7 \%$ y el $1,4 \%$. 


\begin{tabular}{|c|c|c|}
\hline & Autores & Mensajes \\
\hline Barcelona & 9,8 & $\overline{8,2}$ \\
\hline Complutense de Madrid & 8,8 & 6,0 \\
\hline Carlos III & 6,9 & 14,6 \\
\hline Autónoma de Madrid & 5,9 & 5,2 \\
\hline Zaragoza & 5,9 & 4,3 \\
\hline Granada & 4,9 & 5,6 \\
\hline Murcia & 4,9 & 3,4 \\
\hline Extremadura & 3,9 & 2,1 \\
\hline La Coruña & 3,9 & 5,6 \\
\hline Castilla-La Mancha & 2,9 & 5,6 \\
\hline Pompeu Fabra & 2,9 & 1,7 \\
\hline Salamanca & 2,9 & 3,0 \\
\hline Valencia & 2,9 & 1,3 \\
\hline Málaga & 2,0 & 0,9 \\
\hline País Vasco & 2,0 & 0,9 \\
\hline Politécnica de Madrid & 2,0 & 8,2 \\
\hline Politécnica de Valencia & 2,0 & 0,9 \\
\hline Pública de Navarra & 2,0 & 4,7 \\
\hline Alcalá de Henares & 1,0 & 0,4 \\
\hline Almería & 1,0 & 0,4 \\
\hline Cádiz & 1,0 & 0,4 \\
\hline Católica de Ávila & 1,0 & 0,4 \\
\hline Córdoba & 1,0 & 0,4 \\
\hline Europea de Madrid & 1,0 & 0,4 \\
\hline Girona & 1,0 & 0,9 \\
\hline Internacional de Andalucía & 1,0 & 0,4 \\
\hline CEU Luis Vives & 1,0 & 1,3 \\
\hline Oberta de Catalunya & 1,0 & 0,9 \\
\hline Las Palmas de Gran Canaria & 1,0 & 0,9 \\
\hline Politécnica de Cataluña & 1,0 & 3,0 \\
\hline Pontificia de Salamanca & 1,0 & 0,4 \\
\hline Santiago de Compostela & 1,0 & 0,4 \\
\hline Otras univs. españolas & 1,0 & 0,4 \\
\hline Universidades no españolas & 8,5 & 6,8 \\
\hline
\end{tabular}

Tabla 6: Porcentajes de las universidades de los autores de los mensajes

En cuanto a las universidades españolas, se revela en la tabla 6 que es la de Barcelona la que tiene a un mayor número de personas interviniendo en los debates, pero que desde la Carlos III de Madrid se envían más mensajes. En cualquier caso, las universidades madrileñas se encuentran de manera destacada en el grupo de cabeza (Autónoma, Complutense, Politécnica y Carlos III).

Por último, indicar que se ha observado en la evolución cronológica que las personas no acostumbran a ser regulares a lo largo de los años en su participación en los debates, sino que concentran sus colaboraciones en unos meses y luego no acostumbran a contribuir de nuevo en las discusiones.

\subsection{Análisis temático}

\subsubsection{Datos generales}

IweTel se muestra como herramienta imprescindible para la comunicación y la cooperación profesional. Así, la categoría temática dominante es el anuncio de cursos, eventos y convocatorias, y, en segundo lugar, el intercambio de información.

Descendiendo en el análisis a las diferentes categorías (tabla 7), dentro del intercambio de informa- ción, las peticiones son con mucho las más numerosas, aunque se constata que su número cae en picado con el paso del tiempo (sobre todo en el 2000) seguramente por efecto de la moderación, que cercena consultas demasiado generales o poco relacionadas con la temática de la lista.

\section{«Si bien parece haberse sol- ventado el problema del exceso en el envío de mensajes, la difi- cultad que se plantea ahora es evitar que la pasividad se ins- taure en la lista»}

Sin embargo, la cantidad de respuestas no varía sensiblemente, ni siquiera en el último año, aunque proporcionalmente se acercan paulatinamente al número de solicitudes de información. A este respecto cabe indicar que no todas las preguntas obtienen respuestas:

- una minoría recibe un número desmesurado de contestaciones (como en los anteriormente comentados casos de los temas de los patronos y del cine).

- una mayoría es respondidas por medio de la lista o a título particular; esto último resulta insondable, aunque no debe ser nimio a juzgar por los escasos suscriptores que reinciden en la pregunta ante la falta de respuesta.

-finalmente, las hay que no obtienen sino silencio. De cualquier modo, es muy difícil saber en qué grado se da cada una de estas casuísticas.

Por último, la difusión de las respuestas recibidas va incrementándose, principalmente a título porcentual pasando del $4,3 \%$ al $13,7 \%$ de peticiones que hacen públicos los resultados de tales consultas. De todas maneras, y a pesar del aumento, es una cifra realmente baja si se considera que en toda lista de distribución rige una norma no escrita por la que se debe procurar dar tanto o más de lo que se recibe para optimizar el fondo común de experiencia compartida. Quizás los suscriptores no están dispuestos a compartir su información por motivos de descuido, dejadez, o egoísmo temeroso de perder algo propio de cierto valor si se divulga.

En lo que a anuncios se refiere, apenas sufren variación de un año a otro los cursos (cuya oferta parece mantenerse) y los eventos (siguen celebrándose las mismas jornadas, congresos, conferencias y similares). No pocas veces se ha manifestado en la lista la sensación de multiplicación de eventos, aunque quizás se deba más a su concentración en unos pocos meses del año que a un aumento real de su número. Caso aparte es el de las convocatorias, que sorprendentemente au- 


\begin{tabular}{|c|c|c|c|c|c|c|c|c|c|c|c|c|c|c|c|}
\hline & \multicolumn{3}{|c|}{ Intercambio de información } & \multicolumn{3}{|c|}{ Anuncios } & \multicolumn{2}{|c|}{ Novedades } & \multirow{2}{*}{ Div. } & \multirow[b]{2}{*}{ Dupl. } & \multirow{2}{*}{ Pub-e } & \multirow{2}{*}{ Meta } & \multirow{2}{*}{ Debate } & \multirow[b]{2}{*}{ Vacios } & \multirow[b]{2}{*}{ Repet. } \\
\hline & Petición & Respuesta & Divulgación & Curso & Evento & Conv. & Bibl. & Prof. & & & & & & & \\
\hline 1998 & 27,6 & 8,4 & $1,2(4,3)$ & 6,2 & 8,5 & 3,9 & 3,7 & 7,7 & 6,8 & 4,0 & 5,6 & 1,1 & 7,0 & 5,9 & 2,3 \\
\hline 1999 & 22,7 & 9,2 & $1,3(5,9)$ & 6,3 & 7,0 & 5,2 & 4,6 & 7,4 & 7,7 & 3,2 & 7,1 & 1,4 & 7,9 & 6,5 & 2,5 \\
\hline 2000 & 20,2 & 11,4 & $2,8(13,7)$ & 8,3 & 9,0 & 7,6 & 4,5 & 9,0 & 8,1 & 5,9 & 0,1 & 0,8 & 11,0 & 1,0 & 0,4 \\
\hline Total & 23,8 & 9,5 & $1,7(7,0)$ & 6,8 & 8,0 & 5,3 & 4,2 & 7,9 & 7,5 & 4,2 & 4,7 & 1,1 & 8,4 & 4,8 & 1,9 \\
\hline
\end{tabular}

Tabla 7: Porcentajes de las diferentes categorías por años (entre paréntesis porcentaje de «Difusiones» frente al total de «Peticiones»)

mentan un 50\% entre 1998 y 2000 y pasan del 3,9\% al $7,6 \%$ del total de mensajes remitidos.

Las novedades (bibliográficas y profesionales), los mensajes de temática variada (diversos) y el ofrecimiento de duplicados aumentan unánimemente a nivel proporcional; en cuanto a la cantidad de mensajes, estas tipologías varían poco en uno u otro sentido. En lo referente a las novedades, IweTel es poco utilizada para difundir novedades bibliográficas quizás porque el área de los profesionales de la información se vea absorbida por el empirismo laboral cotidiano y la producción científica sea moderada. No se puede decir lo mismo de las novedades profesionales (que son el doble de mensajes que para el caso de la bibliografía).

Cuestión a mencionar es el uso que se hace de las novedades: la moderación ha frenado el envío de publicidad más o menos manifiesta, con lo que, desde entonces, ésta se ha diluido para pasar desapercibida sobre todo en la categoría novedades, donde se han incrementado los mensajes con ánimo comercial que bordean el límite de lo permisible. Este comportamiento también ha sido advertido por MacLennan para Serialst.

\section{«La motivación de pertenecer a IweTel es recibir información y mantenerse al día más que in- tercambiar ideas o contactar con otras personas con intere- ses comunes»}

La moderación se muestra de manera contundente en la evolución de otras tipologías: las publicaciones electrónicas desaparecen en el 2000, y los mensajes sobre la lista (metatema) y los vacíos (incluyendo los repetidos) tienen una presencia anecdótica o insignificante. En este aspecto, y teniendo presente que la mayoría de los mensajes "metatema" eran intervenciones de los administradores ante un uso equívoco de la lista, la efectividad de la moderación es incuestionable.

Por último, se incrementa el número de mensajes que forman parte de debates (que no la cantidad de discusiones), incluso proporcionalmente, pasando del $7 \%$ al $11 \%$ del total enviados. Este aumento ha venido dado por el interés del tema que se trataba, y no ha requerido de ningún acicate por parte de los administradores de la lista.
Analizados por grandes grupos (tabla 8), los porcentajes varían poco: el grupo más numeroso de mensajes (en torno a la mitad) corresponde a los anuncios; el segundo en tamaño es el de los mensajes relacionados con el intercambio de información (aproximadamente un tercio); el resto lo forman debates y mensajes vacíos que, si bien empiezan con un tamaño equiparable, finalmente los primeros aumentan considerablemente y los segundos tienden a desaparecer.

Observando esta última tabla desde una perspectiva diacrónica, resulta equívoco considerar únicamente los totales, pues no reflejan los cambios que son fruto de la implantación de la moderación, ni la nueva tendencia que ésta conlleva, ni, en definitiva, la evolución de la lista.

\subsubsection{Los debates: ¿sobre qué se discute en IweTel?}

Los habituales períodos de calma de la lista se ven salpicados por momentos de efervescencia cuando alguien saca a colación un asunto que suscita interés (o que incluso puede herir alguna susceptibilidad): los debates.

En el presente apartado no se pretende reproducir los argumentos esgrimidos en cada debate, ni analizar cómo se desarrollan las líneas temáticas de las discusiones, sino observar qué temas se tratan.

De acuerdo con lo indicado anteriormente, se han considerado como tales a aquellos que superen los cuatro mensajes, puesto que hasta tal número apenas alcanzan a ser un rápido intercambio de pareceres, un fogonazo, y aun ni eso. En esta enunciación se ha considerado a Feliu (2000) en lo que él llama "líneas temáticas". No se ha seguido, en cambio, a Bar-Ilan y Assouline (1997) en su propuesta de considerar tres mensajes como el mínimo que conforma una discusión porque al aplicarlo a IweTel daba como resultado mucho ruido.

Los debates son el tipo de discurso más complejo de las listas, pues muchos parecen conversaciones habladas y pueden derivar de unas o provocar otras. Cabe la posibilidad de que una discusión esté "incrustada", a decir de McElhearn (1996), en otra, o que flecos de un tema puedan devenir otro diferente. Así, no sería extraño que las respuestas a una pregunta acaben originando un debate que, a su vez, puede provocar diferentes reacciones, como por ejemplo cambios en la propia naturaleza de la lista. Otras veces son provocados por un mensaje mal entendido o malintencionado 
que provoca una discusión vivísima que acaba requiriendo de la intervención del administrador de la lista, sobre todo cuando ésta no es moderada.

La noción de tema en la conversación es todavía vaga, la dinámica exacta de cómo evoluciona no es fácilmente descriptible. Para complicarlo aún más, el tema anunciado en el subject del mensaje no siempre ilustra o coincide con el contenido del propio mensaje. Incluso no acostumbra a ser fácil distinguir los turnos del debate.

Frente a la linealidad discursiva del anuncio, la solicitud de información y el resto de tipologías, el debate es mucho más complejo, amorfo y multidimensional. Así, por ejemplo, muchas de las discusiones tienen un final brusco: simplemente dejan de enviarse mensajes de este tipo de un día para otro. Incluso es raro que se remita a IweTel un resumen del debate que acaba de finalizar.

En resumidas cuentas, la temática de los debates podría dividirse en cuatro grandes grupos (aunque los dos primeros guardan una estrecha relación):

-Problemas laborales: se aborda la falta de definición en la escala administrativa, la discriminación por medio de becas o voluntarios, también en las convocatorias y en el acceso a plazas; se denuncia el intrusismo por parte de titulados en otros estudios que no sean los propios de la Biblioteconomía y la Documentación, etc.

-Funciones de la biblioteca: se reclama una mayor divulgación de las bibliotecas y de los servicios que presta; se cuestiona las funciones que cumple en algunas ocasiones (como sala de estudio, por ejemplo); se denuncia la marginación profesional y su falta de reconocimiento; se plantea la denominación de la profesión (como si fuera única y monolítica).

-Uso de la lista: se protesta contra el uso abusivo e insustancial que se hace de la lista con temas (supuestamente) ajenos al interés general.

-Diversos: se discute sobre el depósito digital nacional, sobre los diferentes soportes, sobre el libro digital, o sobre la gratuidad del $B O E$, por ejemplo.

Siguiendo la tabla 9, las dos primeras áreas ocupan a la mayoría de los debates, es más, suelen ser las discusiones con mayor número de mensajes y mayor duración. El tercer tema aparece con fuerza y de manera

\begin{tabular}{|r|r|r|r|r|}
\hline & $\begin{array}{c}\text { Intercambio } \\
\text { de información }\end{array}$ & $\begin{array}{c}\text { Anuncios } \\
\text { y novedades }\end{array}$ & Debate & Vacíos \\
\hline $\mathbf{1 9 9 8}$ & 37,2 & 47,5 & 7,0 & 8,2 \\
\hline $\mathbf{1 9 9 9}$ & 33,2 & 49,9 & 7,9 & 9,0 \\
\hline $\mathbf{2 0 0 0}$ & 34,4 & 53,1 & 11,0 & 1,5 \\
\hline Total & 35,0 & 49,9 & 8,4 & 6,7 \\
\hline
\end{tabular}

Tabla 8: Porcentajes de los grandes grupos de categorías por años repetida en 1999, llevando posteriormente a la moderación de la lista.

El último grupo se da de manera esporádica y está formado por debates escuetos en tamaño y duración; a pesar de su diversidad, parece mostrar que el único tema ajeno al ámbito laboral que preocupa a los profesionales de la información son los soportes digitales, su perdurabilidad y su conservación. De pura discreción, suelen pasar inadvertidos.

Merece destacarse que, a lo largo de los años, los dos primeros grupos han sido voluminosamente predominantes en las discusiones que se han desarrollado, y que la moderación no ha reducido su número: de hecho, en el año 2000 coparon más del $70 \%$ de debates y del $80 \%$ de mensajes enviados dentro de esta tipología.

En concreto, se repite viciosamente el tema del intrusismo profesional, ligado al de la marginación y discriminación laboral (en especial, las becas) y, a título conclusivo, al del colegio profesional. Estas discusiones suelen estar más movidas por un impulso visceral que por un ánimo constructivo, puesto que, al margen de la conocida relación de protestas, apenas hay voluntad de llevar a cabo un compromiso, de redactar una carta abierta, de plantear una propuesta. Ni siquiera los interlocutores válidos para estas críticas (presidentes de asociaciones y colegios profesionales) suelen dar señales de vida, convencidos, seguramente, de la esterilidad de recoger el testigo de la protesta.

Todo ello no parece ser más que un reflejo de la crisis de identidad profesional y del escaso nivel de consideración social, académico y, sobre todo, laboral que tiene la profesión bibliotecaria (que conforma el grueso de los suscriptores de IweTel). Ésta ofrece la impresión de utilizar la lista de distribución como diván donde enfrentarse a sus fantasmas y obtener el calor corporativo con un lamento autocomplaciente. Aunque ello no ha de ser necesariamente negativo, pues autores como Ray (1996) plantean el valor de disponer de un foro que devenga válvula de escape de las frustraciones laborales diarias.

\subsubsection{El ciclo vital de IweTel}

Conociendo los inicios de IweTel y a la luz de los datos analizados, ¿qué camino ha seguido esa lista de distribución hasta ahora?, ¿en qué estado se encuentra?, ¿qué dirección puede intuirse que seguirá en adelante?

Tales preguntas pueden responderse por medio de la propuesta que Nagel (1994) elaboró sobre el ciclo natural de las listas de discusión:

1. Entusiasmo inicial: reacción positiva de los primeros suscriptores ante la novedad de la herramienta y 
la constatación de su potencial de comunicación y de intercambio profesional.

2. Proselitismo: etapa muy unida a la anterior (en este caso, pueden considerarse como una sola) y que correspondería al primer año de IweTel, sobre la que se hace difusión tanto en revistas (Information world en español) como en jornadas y congresos (Hípola, Baiget, Muñoz-Cañavate, 1994) e incluso trípticos.

3. Crecimiento: aumenta el número de suscriptores, generando cada vez más debates. En esta etapa el aumento de usuarios de la lista va parejo al de la difusión de internet y el correo electrónico, y llegaría hasta 1997, cuando la lista es migrada a los servidores de RedIris a causa de su tamaño.

4. Sentimiento de comunidad: etapa "clásica" de IweTel, de desarrollo pleno. Coincidiría, fundamentalmente, con 1998.

5. Incomodidad con la diversidad: el gran número de mensajes (sobre todo cuando se concentra su envío en pocos días) provoca cada vez más debates sobre el uso de la lista y sobre su propia naturaleza. Como resultado IweTel deviene moderada el 30 de noviembre de 1999.

6. Llegados a este punto pueden darse dos posibilidades ni sucesivas, ni mutuamente excluyentes:

a) autocomplacencia orgullosa y estancamiento: se repiten temas menores en el debate y solicitudes de información.

b) madurez: unos pocos se borran, el resto de usuarios se mantiene cerca del punto 4, saltando al 5 brevemente cada cierto tiempo, pero la lista se mantiene satisfactoriamente.

Ante esa disyuntiva, la moderación ha permitido que IweTel no acabe en el punto a), sino que llegue al b), aunque esta afirmación requiere de matización, pues tal dicotomía no es hermética. Tanto es así que IweTel, a pesar de haber alcanzado la madurez como lista de distribución, tiene algún rasgo de autosatisfacción y, sobre todo, de estancamiento y conformismo.

Por otra parte, si bien parece haberse solventado el problema del exceso en el envío de mensajes, la dificultad que se plantea ahora es evitar que la pasividad se instaure en la lista. A este respecto, Echavarría (1995) cita ilustrativamente la regla 80/20: aproximadamente el $80 \%$ de intervenciones están hechas por el $20 \%$ del total potencial de participantes. Otros autores afirman que mientras que el $10 \%$ interviene en alguna ocasión, el $90 \%$ no lo hace nunca.

La falta de concreción en el enfoque puede llevar al silencio o la frustración de muchos suscriptores potencialmente valiosos.
Es más, la repetición de temas suele provocar el aburrimiento y la huida de los suscriptores más veteranos del grupo. La continua llegada de nuevos participantes puede provocar inestabilidad o decadencia, salvo que las listas cuenten con unos objetivos claramente definidos (y un ánimo decidido en su aplicación) y una minoría creativa implicada en su dinámica.

IweTel deberá contar con esa minoría activa que dinamice y corrija el declive del grupo. Ésta no se mantiene sin cierta reciprocidad y, sin embargo, los suscriptores no parecen estar motivados a contribuir al esfuerzo común, sino a disfrutar de los esfuerzos ajenos. Su silencio, por otro lado, contagia, coarta a los demás o crea una situación de desconfianza perniciosa. Ningún grupo, a la larga, tolera un número demasiado alto de gente que nunca aporta nada sin ver resentido su buen funcionamiento.

En definitiva, la falta de participación en las listas es una disfunción típica en grupos humanos y por lo tanto forma parte de la propia vida de una lista y de cualquier reunión presencial.

El último estadio del crecimiento natural de IweTel sería, quizás, la creación de comunidades virtuales de usuarios (cvus) donde se estructurasen, sistematizasen y gestionasen los recursos y servicios que ya se encuentran invertebrados en la lista de distribución. Queda aún por delante la consolidación del desarrollo de las cvus existentes, y observar si en el modelo que se plantease a IweTel tendrían cabida todos sus suscriptores (y cómo).

\section{Conclusiones: IweTel, ¿para qué?}

Uno de los problemas de las listas es el desbordamiento por el envío de cantidades excesivas de mensajes. IweTel lo ha solventado con la moderación a priori, con todas las objeciones que puedan achacarse (pérdida de la comunicación y la interacción espontánea e inmediata que permite el foro no moderado). De eso se desprende que cuanto mayor sea una lista, más necesidad tiene de moderación ante el peligro de que disminuyan las posibilidades de cumplir sus objetivos.

El siguiente paso es conseguir mantener un mínimo de calidad para lograr ser el germen de una cvu, si, como afirma Feliu (1999), "una lista está destinada a su propia destrucción en un período variable durante el cual los suscriptores irán cambiando, los contenidos se repetirán y el ruido o el silencio serán insoportables".

Tal y como se ha comprobado en este texto, la motivación de pertenecer a IweTel es recibir información y mantenerse al día más que intercambiar ideas o contactar con otras personas con intereses comunes. Indiscutiblemente se comparte información y se potencian las relaciones de apoyo y colaboración entre sus 


\begin{tabular}{|c|c|c|c|}
\hline Tema & $\mathrm{N}^{\circ}$ mensajes & Fecha inicio & Fecha final \\
\hline \multicolumn{4}{|l|}{1998} \\
\hline $\begin{array}{l}\text { Ambigüedad en la denominación y funciones de los cuerpos y } \\
\text { escalas del funcionariado }\end{array}$ & 11 & 22-IV-1998 & 28-IV-1998 \\
\hline Ferias y promoción y divulgación de la biblioteca & 21 & 27-V-1998 & 1-VI-1998 \\
\hline Validez y la necesidad de las certificaciones & 8 & $23-V-1998$ & 2-VI-1998 \\
\hline Pervivencia del papel frente a los medios electrónicos & 7 & $26-V-1998$ & 28-V-1998 \\
\hline Intrusismo laboral & 27 & 2-VI-1998 & 15-Vl-1998 \\
\hline Polémica lingüística & 30 & $25-\mathrm{Vl}-1998$ & 13-VII-1998 \\
\hline Papel de la biblioteca en la defensa de la libertad de expresión & 12 & 27-VII-1998 & $5-\mathrm{VIII}-1998$ \\
\hline $\begin{array}{l}\text { Disponibilidad de apuntes de biblioteconomía y la función de } \\
\text { las bibliotecas como salas de estudio }\end{array}$ & 18 & $29-\mid X-1998$ & $7-X-1998$ \\
\hline Desarrollo de catálogos colectivos & 6 & $4-\mathrm{XI}-1998$ & $6-\mathrm{XI}-1998$ \\
\hline Uso de terminología en bibliotecas: ¿lector, usuario o cliente? & 5 & $7-\mathrm{XI}-1998$ & $10-\mathrm{XI}-1998$ \\
\hline Becas abusivas y discriminación laboral & 27 & $11-X I-1998$ & $25-\mathrm{XI}-1998$ \\
\hline Depósito del patrimonio digital en bibliotecas nacionales & 5 & $4-X I I-1998$ & 8-XII-1998 \\
\hline \multicolumn{4}{|l|}{1999} \\
\hline Pervivencia de los diferentes soportes & 18 & $23-11-1999$ & $1-|I|-1999$ \\
\hline $\begin{array}{l}\text { Automatización de los servicios bibliotecarios y acceso a } \\
\text { Internet desde la biblioteca }\end{array}$ & 67 & 15-III-1999 & 14-IV-1999 \\
\hline Marginación e inmovilidad en la profesión & 8 & $5-V-1999$ & 7-V-1999 \\
\hline Gratuidad del BOE & 11 & $6-V-1999$ & 12-V-1999 \\
\hline Necesidad de moderación en IweTel & 26 & 20-V-1999 & 25-V-1999 \\
\hline Recepción de My News en la lista & 24 & $14-\mathrm{VI}-1999$ & 17-VI-1999 \\
\hline Uso de la lista y celebración del día del patrono & 7 & $15-\mid \mathrm{X}-1999$ & $16-I X-1999$ \\
\hline Discriminación laboral, becas, intrusismo, colegio & 33 & $20-1 X-1999$ & 27-IX-1999 \\
\hline Necesidad de marketing político en la profesión & 5 & 3-XII-1999 & 9-XII-1999 \\
\hline \multicolumn{4}{|l|}{2000} \\
\hline Impedimentos lingüísticos en la convocatoria de oposiciones & 19 & $12-\mathrm{I}-2000$ & $13-I-2000$ \\
\hline Discriminación y el intrusismo profesional (voluntariado) & 72 & $19-\mid-2000$ & $7-\mathrm{III}-2000$ \\
\hline Estado de la cuestión de las bibliotecas escolares & 7 & $25-\mid-2000$ & $31-1-2000$ \\
\hline Mal uso de la lista & 8 & $29-11-2000$ & $1-|I|-2000$ \\
\hline Privatización de servicios bibliotecarios & 9 & $13-I V-2000$ & $25-I V-2000$ \\
\hline Servicios bibliotecarios: librerías frente a bibliotecas & 7 & $8-\mathrm{VI}-2000$ & $9-\mathrm{Vl}-2000$ \\
\hline $\begin{array}{l}\text { Pago de inscripción en congresos para coautores } \\
\text { de comunicaciones }\end{array}$ & 9 & 17-VII-2000 & $19-\mathrm{VII}-2000$ \\
\hline Discriminación en el acceso a plazas bibliotecarias & 14 & $8-X-2000$ & $16-X-2000$ \\
\hline Denominación de la profesión & 33 & $7-\mathrm{XI}-2000$ & $28-\mathrm{XI}-2000$ \\
\hline Libro y edición digital & 5 & $13-X I-2000$ & $14-\mathrm{XI}-2000$ \\
\hline Uso de la lista e imagen profesional & 14 & $22-\mathrm{XI}-2000$ & $4-\mathrm{XII}-2000$ \\
\hline Atención al público en la biblioteca & 5 & $27-\mathrm{XI}-2000$ & $28-\mathrm{XI}-2000$ \\
\hline
\end{tabular}

Tabla 9: Temas de debate

miembros, aunque a partir de intervenciones públicas y de manera paralela fuera de la lista. Otros autores (Cothrel, Williams, 1999) apuntan en este sentido: algunas listas de distribución son de hecho "plazas de pueblo"s donde los suscriptores toman un contacto inicial que profundizan con el intercambio de correo electrónico a título privado.

A tenor de lo anterior, si en IweTel (al igual que en listas como Techwrl, Serialst, Pubyac) no se advierte demasiada voluntad de colaborar, de arrimar el hombro y cooperar, ¿cómo van a afianzarse las cvus si requieren de un cambio considerable en los hábitos de trabajo y de una implicación mucho mayor por parte de sus miembros? En vista de los resultados, no se advierte todavía la existencia de una cultura de grupos de discusión.

IweTel parece haber caído desde hace un tiempo en un bucle resignado: para informarse y mantener actualizado nuestro conocimiento de lo que acaece en la profesión hay que estar en IweTel. Lo cual debe valorarse como positivo a pesar de que como herramienta de comunicación profesional se haya demostrado infrautilizada y por ello limitada, y de que a la hora de intentar desarrollar un debate profesional no haya alcanzado el nivel esperado a causa, ciertamente, de la 
obsesión temática y la susceptibilidad reinantes, las cuales serían perfectamente comprensibles si no se dieran en un grado tan exagerado.

Ante el problema de una lista desenfocada y que padezca de gigantismo desbordante, se han planteado diversas alternativas (con desigual resultado); una de ellas considera crear dos listas paralelas:

—una abierta y no moderada, para fomentar la comunicación y la cooperación profesional.

-otra enfocada estrechamente en un tema, que facilite la mejora de la calidad académica y científica de la lista.

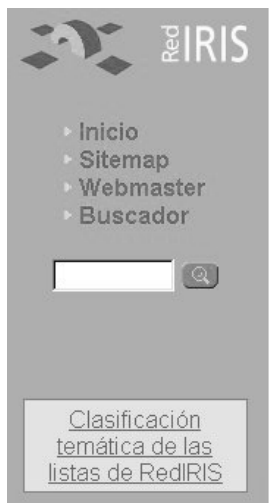

A título final, y como se ha visto en el caso aquí estudiado, una lista de distribución profesional no es sino la plasmación en un foro electrónico de problemas socioprofesionales muy anteriores que, si no insolubles, sí que permanecen latentes y en mayor o menor medida interiorizados, y que los miembros regurgitan cíclicamente con cierta impotencia y amargura.

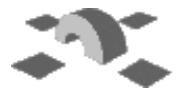

\section{Notas}

1. Merlo/Sorli (1999), Feliu (1999), Pedersen (1996b) y Kollock (1994) proponen en sus textos parámetros evaluativos de calidad de una lista y criterios para que un foro tenga éxito. En un ámbito más restringido, $R e$ dIris plantea una Propuesta para mejorar la calidad académica y científica de las listas: http://www.rediris.es/cvu/publ/calidad.es.html

2. http://listserv.rediris.es/archives/iwetel.html
- Servicios 4 Listas de distribución

Foro para profesionales de

bibliotecas y documentacion.

Información sobre IWETEL

Creada/actualizada: 14/04/1997

IweTel es el principal foro electrónico sobre bibliotecas y documentación que existe en castellano. Fue puesto en marcha en noviembre de 1993 por iniciativa del equipo de redacción de la revista El profesional de la información (antes ME). publicada actualmente por la editorial holandesa Swets \& Zeitlinger Publishers (http://mmw. swets.nl/sps), sobre información, documentación, bibliotecas y sus tecnologias.

En sus primeros años de existencia, la lista fue mantenida en los ordenadores de la empresa SAREnet. Al ser migrada en 1997 a los servidores de RedIRIS (Red académica y de investigación española) lweTel se convirtió pronto en el principal medio electrónico de comunicación para los profesionales del mundo de la

información y la documentación de habla hispana. Swets ha continuado información y la documentación de habla hispana. Swets ha continuado objetivos.

Temas de debate:

- Servicios de información online y en cd-rom.

3. Mensaje 4.946, "Iwetel, lista moderada", de Pedro Hípola, 30 de noviembre de 1999.

4. Obsérvese que, debido a la distribución de los datos, la escala en ambos ejes no sigue la misma proporción del 1 al 10 que del 10 al 100. Se trata de una escala doble logarítmica.

\section{Adaptación que se hace del concepto town hall que aplican en esta} acepción Cothrel y Williams.

\section{Bibliografía}

Archer, Ronald. "INformation IMpact CAse Studies Listserv: 'Inimcas-1'. Analysis of initial use". En: Proceedings of an International Development Research Centre workshop: making a difference. Measuring the impact of information on development. Ottawa: Paul McConnell, 1995, pp. 207-210.

http://www.idrc.ca/books/focus/783/archer.html [Consulta: 12/09/2001]

Bar-Ilan, Judit; Assouline, Betty. "A content analysis of Pubyac: a preliminary study". En: Information technology and libraries, 1997, v. 16, n. 4, dic., pp. 165-174.

Barrueco, José Manuel; García Testal, Cristina; Gimeno Montoro, $\mathbf{M}^{\mathbf{a}}$ José. "Las listas de correo como fuente de información en biblioteconomía y documentación". En: Métodos de información, 1996, v. 3, n. 9, pp. 22-29.

Servicio de Listas de Distribución de RedIRIS

http://www.metodosdeinformacion.com/documentos/1996-09-22.pdf [Consulta: 4/03/2001]

Archivos de IWETEL@LISTSERV.REDIRIS.ES

Foro para profesionales de bibliotecas y documentacion.

\section{Facilidades:}

Búsqueda en archivos

\section{Enviar a la lista}

Suscribirse, abandonar o modificar opciones de suscripción o la dirección de correo-e suscrita

[Gestionar la lista] (Exclusivo para administradores)

Registrese y obtenga una clave para acceder a los archivos

Archivos:

- Diciembre 2001, semana 3

- Diciembre 2001, semana 2

- Diciembre 2001, semana 1

- Noviembre 2001, semana 5

- Noviembre 2001, semana 4

- Noviembre 2001, semana 3
Berge, Zane L.; Collins, Mauri P. "Perceptions of e-moderators about their roles and functions in moderating electronic mailing lists". En: Distance education: an international journal, 2000, v. 21 , n. 1, pp. 81-100.

http://www.emoderators.com/moderators/modsur97.html [Consulta: 6/09/2001]

Burnett, Gary. "Information exchange in virtual communities: a typology". En: Information rese$\operatorname{arch,~2000,~v.~5,~n.~4,~July.~}$

http://informationr.net/ir/5-4/paper82.html [Consulta: $23 / 04 / 2001]$

Burton, Paul F. "Electronic mail as an academic discussion forum". En: Journal of documentation, 1994, v. 50, n. 2, junio, pp. 99-110. 
Castillo Vidal, Jesús. "Comunidades virtuales: la superación de las listas de distribución como foro de reunión y trabajo de profesionales". En: $E l$ profesional de la información, 1999, v. 8, n. 6, junio, pp. 14-28.

Castro Castro, Carlos; Muñoz-Cañavate, Antonio. "Recursos informativos en internet: foros electrónicos de discusión". En: IV Jornadas españolas de documentación automatizada. Oviedo: Aabadom, 1994, pp. 63-72.

Castro Castro, Carlos; Muñoz-Cañavate, Antonio. "Recursos informativos en las redes: análisis de las listas de discusión por un mail list manager: el listserv de la red Bitnet". En: V Jornades catalanes de documentació: Cobdc; Socadi, 1995, pp. 521-528.

Cothrel, Joseph; Williams, Ruth L. "On-line communities: helping them form and grow". En: Journal of knowledge management, 1999, v. 3, n. 1 , pp. $54-60$

Echavarría, Tami; [et al.]. "Encouraging research through electronic mentoring: a case study". En: College \& research libraries, 1995, v. 56, n. 4 , pp. $352-361$

Feliu Jornet, Víctor; Gisbert Cervera, Mercè. Dinámica y evaluación de las listas de distribución de temática educativa. 2000, 15 p.

Feliu, Víctor. Evolución y dinámica de las listas. En: Boletín de la RedIris, dic. 1998-en. 1999, n. 46/47, pp. 99-106.

http://www.rediris.es/list/propi/arti/nv98/evolistas/evolucion-listas.html [Consulta: 4/03/2001]

Feliu, Víctor. “Com avaluar les llistes de distribució?”. En: Métodos de información, 1999, v. 6, n. 31, julio, pp. 41-52.

García Testal, Cristina. "Entrevista a Pedro Hípola". En: Métodos de información, 1999, v. 6, n. 31, julio, pp. 36-39.

Herrero Solana, Víctor Federico. "La utilización de foros de discusión electrónicos como fuente de información sobre la comunidad científica informal". En: Revista General de Información y Documentación, 1996, v. 6 , n. 2 , pp. 219-229.

Hípola, Pedro; Baiget, Tomàs; Muñoz-Cañavate, Antonio. "Iwetel: foro electrónico para los profesionales de la documentación". En: IV Jornadas españolas de documentación automatizada. Oviedo: Aabadom, 1994, pp. 27-33.

Jiménez, J. A.; Padilla, A. “Análisis estratégico de la integración de las listas de distribución en las comunidades virtuales de usuarios". En: Boletín de la RedIris, dic. 1998-en. 1999, n 46/47, pp. 107-114.

Kilian, Crawford. "The Passive-Aggressive Paradox of On-Line Discourse". En: Technos quarterly for education and technology, 1994, v. 3, n. 2, summer

http://www.technos.net/journal/volume3/2kilian.htm [Consulta: 23/08/2001]

Kollock, Peter; Smith, Marc. Managing the virtual commons: cooperation and conflict in computer communities. 1996.

http://www.sscnet.ucla.edu/soc/faculty/kollock/papers/vcommons.htm [Consulta: 31/03/2001]

Kollock, Peter. Design principles for online communities. 1996. http://www.sscnet.ucla.edu/soc/faculty/kollock/papers/design.htm [Consulta: $31 / 03 / 2001]$

\section{¿Recibes ya EPI en casa?}

Por sólo 65 a $+4 \%$ IVA puedes tener todos los meses tu copia particular y leerla cómodamente cuando quieras.
Mac Lennan, Birdie. "Serialst and the global serials community: the five year evolution of an electronic discussion forum". En: Serials review, 1996, v. 22, n. 3, fall, pp. 1-21.

http://www.uvm.edu/ bmaclenn/serialst5.html [Consulta: 31/03/2001]

Matzat, Uwe. "Informal Academic Communication and Scientific Usage of Internet Discussion Groups". En: Internet research and information for social scientists: Iriss'98. 1998.

http://www.sosig.org/iriss/papers/paper19.htm [Consulta: 6/09/2001]

McElhearn, Kirk. Writing conversation: an analysis of speech events in e-mail mailing lists. October 1996.

http://www.mcelhearn.com/cmc.html [Consulta: 20/04/2001]

Merlo Vega, José Antonio; Sorli Rojo, Ángela. "Las relaciones interprofesionales en las listas de distribución de información y documentación españolas". En: VI Jornadas españolas de documentación. Valencia: Avei, 1998, pp. 597-612.

Merlo Vega, José Antonio; Sorli Rojo, Ángela. "Las listas de distribución como herramienta profesional". En: Métodos de información, 1999, v. 6, n. 31, julio, pp. 53-60.

http://www.metodosdeinformacion.com/documentos/1999-31-53.pdf [Consulta: $20 / 04 / 2001]$

Moliní, Fernando. Propuesta para mejorar la calidad académica y científica de las listas.

http://www.rediris.es/list/propi/calidad.es [Consulta: 21/04/2001]

Nagel, K. Ciclo natural de las listas de distribución. 1994.

http://trueque.org.ar/ciclo.htm [Consulta: 21/04/2001]

Pedersen, Robert C. "A quantitative approach to the description of internet mailing lists". En: The serials librarian, 1996, v. 30, n. 1, pp. 39-47.

Pedersen, Robert C. "Reviewing Internet mailing lists". En: The serials librarian, 1996, v. 30, n. 2, pp. 27-33.

Ray, Eric J. "Techwr-1: a history and case study of a profession-specific listserv list". En: Technical communication, 1996, v. 43, n. 4, nov., pp. 334-338.

http://www.raycomm.com/techwhirlcasestudy.html [Consulta: 10/09/2001]

RedIris. Conceptos básicos sobre las listas de distribución. [documento electrónico]. 1997.

http://www.rediris.es/list/basico.es.html [Consulta: 17/02/2001]

Robinson, Kara L. "People talking to people: making the most of internet discussion groups". En: Online, 1996, Jan.-Feb., v. 20, n. 1, pp. 26-32.

Sanz de las Heras, Jesús. "Servicio de listas de distribución de RedIris". En: Boletín de la RedIris.

http://www.rediris.es/rediris/boletin/33/enfoque2.html

Sanz de las Heras, Jesús. Guía de utilización del Listserv.

http://www.rediris.es/list/utilizacion.html

Talavera Serrano, $M^{\text {a }}$ del Carmen; Puente Bautista, David; Marcelo García, Carlos. "¿Quién habla ahí?: análisis del discurso virtual de los profesionales de la formación". En: Congreso nacional sobre formación del profesorado: evaluación y calidad. Las Palmas, 1998.

http://www.rediris.es/cvu/publ/canarias.es.html [Consulta: 24/05/2001]

José Antonio Ontalba y Ruipérez. Biblioteca Virtual. Universitat Oberta de Catalunya.

jontalba@uoc.edu 